\title{
Meia-Vida do Ametryn em ARgissolo Vermelho-Amarelo e Latossolo Vermelho-Amarelo, COM Diferentes ValoRes DE PH ${ }^{1}$
}

\author{
Determination of Half-Life of Ametryn on Red-Yellow Latosol and Red-Yellow Ultisol with \\ Different $p H$ Values
}

\author{
ANDRADE, S.R.B. ${ }^{2}$, SILVA, A.A. ${ }^{3}$, LIMA, C.F. ${ }^{4}$, QUEIROZ, M.E.L.R. ${ }^{4}$, FRANÇA, A.C. ${ }^{5}$ e \\ D’ANTONINO, L. ${ }^{6}$
}

\begin{abstract}
RESUMO - Objetivou-se com este trabalho determinar a meia-vida ( $\mathrm{t}^{1 / 2}$ ) do herbicida ametryn em Argissolo Vermelho-Amarelo e Latossolo Vermelho-Amarelo, com diferentes valores de $\mathrm{pH}$. Foram utilizados vasos revestidos internamente com filme plástico e preenchidos com 330,0 g de amostras dos solos em estudo (Latossolo Vermelho-Amarelo - LVA com valores de pH corrigidos para 4,4, 4,9 e 5,8, e Argissolo Vermelho-Amarelo - PVA com pH 5,9). As amostras desses solos foram coletadas em pastagens degradadas isentas da aplicação de herbicidas. A essas amostras foi aplicado o ametryn na dose de 2,5 L ha-1. Doze horas após essa aplicação, foram retiradas as primeiras amostras de solo dos vasos, para determinação da concentração no tempo zero, e a cada cinco dias foram retiradas novas amostras de outros vasos, visando à determinação da concentração de ametryn ao longo do tempo. A extração do ametryn da matriz solo foi realizada por Extração Sólido Liquido com Partição em Baixa Temperatura (ESL-PBT), e o herbicida, quantificado por cromatografia liquida de alta eficiência - CLAE. Foi realizado, em paralelo, um teste biológico para determinação indireta da persistência do herbicida. A análise dos dados indicou que a meia-vida ( $\mathrm{t}^{1 / 2}$ ) do ametryn nos solos avaliados foi de 26, 19, 12 e 11 dias para os solos LVA pH 4,4; LVA pH 4,9; LVA pH 5,8; e PVA pH 5,9, respectivamente. Ambos os métodos (cromatografia ou bioensaios) utilizados para avaliação da persistência do ametryn nos solos evidenciaram que a degradação desse herbicida é muito influenciada pelo $\mathrm{pH}$ do solo e pelo teor de matéria orgânica.
\end{abstract}

Palavras-chave: persistência, características do solo, CLAE, teste biológico.

\begin{abstract}
The objective of this study was to determine the half-life $\left(t^{1} / 2\right)$ for the herbicide ametryn in Red-Yellow Latosol (LVA) and Red-Yellow Ultisol (PVA) with different $p H$ values. Thus, plastic pots coated inside with plastic film were filled with $330 \mathrm{~g}$ of samples from the soils under study (LVA with $p H$ values adjusted to 4.4, 4.9 and 5.8, and PVA pH 5.9), collected in degraded pastures without herbicide application. Ametryn was applied on these soil samples at a dose of 5.O ha $L^{-1}$. Twelve hours after application, the first soil samples were extracted from the pots to determine the concentration at zero time, and every five days new samples were removed from the other pots (two pertime) to determine ametryn concentration over time. Ametryn extraction from the soil matrix was performed by Solid Liquid Extraction with Partition at Low Temperature (SLE-PLT) and quantified by liquid chromatography. A biological test for indirect determination of herbicide persistence was also carried out. Results indicated that ametryn half-life (t1/2) on the soils evaluated was 26, 19, 12 and 11 days in LVA soil pH 4.4; pH 4.9; $p H 5.8$ and PVA $p H$ 5.9, respectively. Both methods (chromatography or bioassay) used to evaluate ametryn persistence in soils showed that degradation of this herbicide is strongly influenced by soil pH and organic matter content.
\end{abstract}

Keywords: persistence, soil characteristics, HPLC, bioassay.

Recebido para publicação em 10.8.2009 e na forma revisada em 15.6.2010.

2 Licenciada em Química, M.Sc., <shisleybarcelos@yahoo.com.br>; ${ }^{3}$ D.Sc., Professor Associado do Dep. de Fitotecnia, Universidade Federal de Viçosa - DFT/UFV; ${ }^{4}$ D.Sc., Professor Associado do Dep. de Química, DEQ/UFV; ${ }^{5}$ D.Sc., Professor Adjunto, DAG/UFVJM; ${ }^{6}$ Engo-Agro ${ }^{-}$, D.Sc., Dep. de Fitotecnia, DFT/UFV.

Planta Daninha, Viçosa-MG, v. 28, n. 2, p. 375-383, 2010 


\section{INTRODUÇÃO}

A persistência de um herbicida no solo depende dos processos de dissipação, evaporação, lixiviação, escoamento superficial, absorção pelas plantas e da taxa de degradação física, química e biológica da molécula (Silva et al., 2007). Os processos de degradação químicos, físicos ou biológicos podem resultar na mineralização total do herbicida ou na sua conversão em metabólitos secundários (Nakagawa \& Andrea, 2000). Entre esses processos, maior importância tem sido atribuída à degradação biológica, que está relacionada à atividade dos microrganismos presentes no solo (GrahamBryce, 1981).

Durante o processo de dissipação, uma parte do pesticida aplicado pode permanecer no solo na forma de resíduos, podendo estes ser o próprio composto ou seus metabólitos, permanecendo na forma extraivel ou ligada ao solo (Nakagawa \& Andrea, 2000). O resíduo ligado é formado por meio de ligações de hidrogênio e troca cationica, entre outras, entre a molécula do pesticida e a matéria orgânica do solo. A formação do resíduo ligado pode levar à diminuição da degradação do pesticida e à perda de sua identidade química (Calderbank, 1989). Pode também causar a perda da sua atividade biológica (Gevao et al., 2000), a alteração da sua absorção pelas plantas, a alteração do escoamento superficial, além da lixiviação desses compostos (Nakagawa \& Andrea, 2000).

Herbicida muito utilizado em cana-de-açúcar, o ametryn apresenta persistência média no ambiente de quatro a seis meses em condições tropicais e subtropicais, podendo ser maior que nove meses se usado em doses elevadas, dependendo do clima e tipo de solo. É pouco móvel no perfil do solo, sendo muito sorvido por coloides orgânicos e minerais. Sua sorção pelos coloides é influenciada pelo $\mathrm{pH}$ e teor de matéria orgânica (Silva et al., 2007). Acredita-se que também pode apresentar sorção negativa, dessorção, ocorrendo liberação para as plantas de moléculas anteriormente inativadas pelos coloides do solo (Vivian et al., 2007).

A utilização intensiva de agrotóxicos com a finalidade de obter elevada produtividade agrícola, durante o último século, teve papel fundamental na contaminação ambiental e, ocasionalmente, em águas superficiais
(Filizola et al., 2002). Portanto, existe a necessidade de monitoramento ambiental constante, assim como o desenvolvimento de diferentes métodos analíticos que visem à identificação, quantificação e elucidação do comportamento dos resíduos de herbicidas no solo. Estudos realizados em seis estados dos EUA, divulgados pela Extension Toxicology Network (Extoxnet, 2005), confirmaram a detecção do ametryn em águas superficiais e subterrâneas. Também Mitchell et al. (2005) identificaram 0,3 $\mathrm{g} \mathrm{L} \mathrm{L}^{-1}$ de resíduos de ametryn e outros quatro herbicidas em águas de rios pertencentes à região de Mackay Whitsunday, na Austrália. Singh (2003) relata que vários estudos em lençóis aquíferos subterrâneos de regiões agrícolas dos Estados Unidos têm apresentado contaminações por herbicidas. Monteiro et al. (2008) comprovaram a contaminação de cursos d'água por ametryn, atrazine e simazine no Estado de São Paulo, em regiões com intenso cultivo de cana-de-açúcar.

A persistência de um composto no ambiente é normalmente medida pela meia-vida, que é definida como o tempo necessário para que ocorra a dissipação de $50 \%$ da quantidade inicial do herbicida aplicado (Silva et al., 2007). A meia-vida de um herbicida varia com o solo e o clima e é extremamente importante para predizer o risco de contaminação de lençóis freáticos conforme modelo proposto por Gustafson (1989).

Objetivou-se com este trabalho determinar a meia-vida ( $\mathrm{t} 1 / 2)$ do ametryn em um Latossolo Vermelho-Amarelo (LVA) com diferentes valores de $\mathrm{pH}$ e em um Argissolo VermelhoAmarelo (PVA).

\section{MATERIAL E MÉTODOS}

Amostras de um Latossolo VermelhoAmarelo (LVA) e de um Argissolo VermelhoAmarelo (PVA) foram coletadas na profundidade de 0 a $20 \mathrm{~cm}$ em áreas de pastagens degradadas, isentas da aplicação de herbicidas, da região de Viçosa-MG. As amostras do LVA foram divididas em três partes; duas delas foram incubadas com $\mathrm{CaCO}_{3}$ por 90 dias, visando obter amostras com valores diferentes de $\mathrm{pH}$. Após esse período, todas as amostras foram caracterizadas quanto às características químicas e físicas (Tabela 1). 
Tabela 1 - Caracterização física e química e classificação textural das amostras de solo utilizadas no experimento. Viçosa - MG

\begin{tabular}{|c|c|c|c|c|c|c|c|c|c|c|}
\hline \multicolumn{11}{|c|}{ Análise granulométrica } \\
\hline Solo & Argila & Silte & Areia fina & \multicolumn{2}{|c|}{ Areia grossa } & \multicolumn{5}{|c|}{ Classificação textural } \\
\hline LVA & 44 & 15 & 17 & \multicolumn{2}{|c|}{24} & \multicolumn{5}{|c|}{ Argiloso } \\
\hline PVA & 25 & 16 & 22 & \multicolumn{2}{|c|}{37} & \multicolumn{5}{|c|}{ Franco-Argilo arenoso } \\
\hline \multicolumn{11}{|c|}{ Análise química } \\
\hline \multirow{2}{*}{ Solo } & $\mathrm{pH}$ & $\mathrm{P}$ & $\mathrm{K}^{+}$ & $\mathrm{Ca}^{++}$ & $\mathrm{Mg}^{++}$ & $\mathrm{H}+\mathrm{Al}$ & $\begin{array}{l}\text { CTC } \\
\text { total }\end{array}$ & $\mathrm{V}$ & $\mathrm{m}$ & MO \\
\hline & $\left(\mathrm{H}_{2} \mathrm{O}\right)$ & \multicolumn{6}{|c|}{$\left(\mathrm{cmol}_{\mathrm{c}} \mathrm{dm}^{-3}\right)$} & \multicolumn{2}{|c|}{$(\%)$} & $\left(\right.$ dag kg $\left.^{-1}\right)$ \\
\hline LVA & 4,4 & 1,7 & 27 & 0,6 & 0,2 & 8,25 & 2,29 & 10 & 63 & 1,70 \\
\hline LVA & 4,9 & 1,7 & 27 & 1,0 & 0,4 & 7,26 & 2,37 & 15 & 44 & 1,70 \\
\hline LVA & 5,8 & 1,7 & 27 & 9,2 & 2,6 & 0,99 & 11,87 & 92 & 0 & 1,70 \\
\hline PVA & 5,9 & 5,2 & 81 & 2,8 & 1,4 & 2,64 & 4,47 & 63 & 0 & 2,55 \\
\hline
\end{tabular}

Análises realizadas no Laboratório de Análises de Solo Viçosa, segundo a metodologia da Empresa Brasileira de Pesquisa Agropecuária EMBRAPA (1997).

Posteriormente, preencheram-se vasos previamente impermeabilizados com filme de polietileno com $330,0 \mathrm{~g}$ das amostras dos solos em estudo, as quais foram tratadas com ametryn na dose de 2,5 $\mathrm{kg} \mathrm{ha}^{-1}$. A aplicação do ametryn foi realizada à superfície dos vasos, com pulverizador de precisão equipado com bico TT 110.02, aplicando-se o equivalente a 150,0 L ha-1 de calda. Depois disso, os vasos com os diferentes solos foram encaminhados à casa de vegetação do Departamento de Fitotecnia da Universidade Federal de Viçosa e irrigados até que atingissem uma condição próxima à capacidade de campo. Foi retirado todo o solo contido em dois vasos de cada amostra, 12 horas após a aplicação do ametryn, visando à determinação da concentração inicial do herbicida. Posteriormente, em intervalos de cinco dias, foram obtidas novas amostras, com a retirada total do solo de dois vasos por vez (duplicata), para novas análises, a fim de determinar a concentração do herbicida no solo em laboratório. Na extração do ametryn do solo em laboratório, as amostras foram quarteadas com o intuito de reduzir a massa a ser utilizada. Em seguida, as amostras foram submetidas à extração sólidolíquido com partição em baixa temperatura (ESL-PBT) (Vieira et al., 2007). A quantificação do ametryn no solo foi sempre realizada em triplicata, por cromatografia líquida de alta eficiência - CLAE. Os dados obtidos foram submetidos à análise de regressão para interpretação dos resultados.
A fim de obter a confirmação do resultado cromatográfico, foi escolhido, aleatoriamente, o extrato de uma amostra analisada por determinação em cromatografia gasosa acoplada a um espectrômetro de massa (CG-MS). Além disso, também na confirmação dos resultados de meia-vida obtidos por cromatografia, foram escolhidas aleatoriamente amostras dos solos, utilizando-se o bioensaio. Para isso, cultivou-se o pepino (Cucumis sativus) em vasos contendo essas amostras, previamente tratadas com o ametryn aos 0, 15, 30 e 45 dias após a aplicação do herbicida.

A solução-estoque do ametryn foi preparada a partir do padrão, apresentando pureza de $98,3 \%$, solubilidade de $200 \mathrm{mg} \mathrm{L}^{-1}\left(22{ }^{\circ} \mathrm{C}\right)$, pKa de 4,1 e log Kow de 2,63, na concentração de $1.000 \mu \mathrm{g} \mathrm{mL}^{-1} \mathrm{em}$ acetonitrila; as soluções de trabalho foram preparadas a partir da diluição desta. Essas soluções eram de concentrações crescentes $\left(0,01\right.$ a $\left.1,2 \mathrm{mg} \mathrm{L}^{-1}\right)$ do herbicida em acetonitrila, visando à obtenção da curva de quantificação do ametryn (curva-padrão). As amostras foram quantificadas a partir da equação da reta obtida pela curva-padrão, que teve seus pontos checados periodicamente, para garantir a confiabilidade da análise.

Com intuito de acompanhar a porcentagem de extração obtida a cada etapa do experimento, foram realizadas fortificações de amostras de solo. Para isso, adicionaram-se $100 \mu \mathrm{L}$ da solução-padrão do herbicida na concentração de $100 \mathrm{mg} \mathrm{L}^{-1}$ a 2,00 g de amostra de solo seco 
pesado em balança analítica de precisão, obtendo-se a concentração final de $5,0 \mathrm{mg} \mathrm{kg}^{-1}$. Depois de devida homogeneização da amostra, os frascos que continham a mistura solo + herbicida foram mantidos abertos, à sombra, para evaporação do excesso de acetonitrila. O tempo de fortificação foi de quatro horas, com posterior extração, a qual foi realizada nas mesmas condições e simultaneamente com as amostras reais.

Neste trabalho foi utilizada a metodologia otimizada por De Paula (2007), o qual trabalhou com o mesmo herbicida e matriz de solo. A análise cromatográfica foi realizada no Laboratório de Sintese de Agroquímicos (LASA) do Departamento de Química da UFV. O equipamento utilizado foi um cromatógrafo líquido de alta eficiência (CLAE) Shimadzu SPD 2a. A validação do método ESL-PBT foi feita considerando seletividade, linearidade, limite de detecção (LD), limite de quantificação (LQ), precisão e exatidão (Tabela 2). Os valores encontram-se em conformidade com a literatura de análise de pesticidas (INMETRO, 2003; Brito et al., 2003; Ribani et al., 2004), com média de recuperação entre 70 e $120 \%$ e CV < $20 \%$.

Para confirmação dos resultados obtidos por CLAE, realizaram-se injeções de padrão de $10 \mathrm{mg} \mathrm{L}^{-1}$ e de amostra aleatória em cromatógrafo a gás acoplado a espectrômetro de massa (CG-MS), marca Shimadzu, modelo QP5050A. A coluna foi a DB5, com $30 \mathrm{~m}$ de comprimento, 0,25 mm de diâmetro interno e filme de 0,25 $\mu \mathrm{m}$ de espessura. As condições das análises cromatográficas estão descritas na Tabela 3.

A avaliação do índice de intoxicação das plantas-teste pelo herbicida foi realizada atribuindo-se notas de 0 (ausência de intoxicação)

Tabela 2 - Principais parâmetros avaliados na validação do método de ESL-PBT com análise por CLAE

\begin{tabular}{|l|c|}
\hline Limite de detecção $\left(\mathrm{mg} \mathrm{L}^{-1}\right)$ & 0,01 \\
\hline Limite de quantificação $\left(\mathrm{mg} \mathrm{L}^{-1}\right)$ & 0,04 \\
\hline Porcentual de recuperação (\%) & 91,4 \\
\hline Coeficiente de variação (\%) & 3,8 \\
\hline Curva analítica & $\hat{\mathrm{Y}}=152393,9 \mathrm{x}+48,62$ \\
\hline Coeficiente de correlação (r) & 0,999 \\
\hline
\end{tabular}

a 10 (morte da planta), de acordo com escala da EWRC (1964) modificada (Tabela 4).

\section{RESULTADOS E DISCUSSÃO}

A curva-padrão para o ametryn em acetonitrila obtida por CLAE está representada

Tabela 3 - Características dos métodos cromatográficos empregados na determinação por CLAE e por CG-MS para o ametryn

\begin{tabular}{|c|c|}
\hline \multicolumn{2}{|c|}{$\begin{array}{l}\text { Características cromatográficas do método de quantificação } \\
\text { do ametryn }\end{array}$} \\
\hline Fase estacionária & $\begin{array}{l}\text { Sílica-octadecil } \\
\quad(\mathrm{C} 18)\end{array}$ \\
\hline \multicolumn{2}{|c|}{ CLAE } \\
\hline$\varnothing$ partícula $(\mu \mathrm{m})$ & 5,0 \\
\hline Comprimento de onda $(\mathrm{nm})$ & 245 \\
\hline Comprimento da coluna (mm) & 250 \\
\hline$\varnothing$ interno da coluna & 4,0 \\
\hline Fase móvel & $\begin{array}{l}\mathrm{CH}_{3} \mathrm{CN}: \mathrm{H}_{2} \mathrm{O}\left(\mathrm{H}_{3} \mathrm{PO}_{4}\right) \\
48: 52+0,1 \%\end{array}$ \\
\hline Vazão $\left(\mathrm{mL} \mathrm{min}^{-1}\right)$ & 1,2 \\
\hline Volume de injeção $(\mu \mathrm{L})$ & 20 \\
\hline Tempo de retenção $(\mathrm{min})$ & 13 \\
\hline \multicolumn{2}{|c|}{ CG-MS } \\
\hline Coluna & DB5 \\
\hline Comprimento da coluna $(\mathrm{m})$ & 30 \\
\hline$\varnothing$ coluna $(\mathrm{mm})$ & 0,25 \\
\hline$\varnothing$ filme $(\mu \mathrm{m})$ & 0,25 \\
\hline Temperatura de injeção $\left({ }^{\circ} \mathrm{C}\right)$ & 290,0 \\
\hline Temperatura do detector $\left({ }^{\circ} \mathrm{C}\right)$ & 290,0 \\
\hline Fluxo da coluna $\left(\mathrm{mL} \mathrm{min}^{-1}\right)$ & 1,6 \\
\hline $\begin{array}{l}\text { Programação da temperatura da } \\
\text { coluna }\left({ }^{\circ} \mathrm{C}\right)\end{array}$ & $\begin{array}{l}80^{\circ} \mathrm{C} \text { por } 5 \text { min. } \\
\text { Aumentando a cada } 4 \text { min } \\
\text { até atingir } 285^{\circ} \mathrm{C} .\end{array}$ \\
\hline Tempo de retenção (min) & 34,7 \\
\hline Faixa de relação massa/carga $(\mathrm{m} / \mathrm{z})$ & $30,0-700,0$ \\
\hline Volume de injeção $(\mu \mathrm{L})$ & 1,0 \\
\hline Razão de split & $: 1$ \\
\hline
\end{tabular}

Tabela 4 - Escala de sintomas de intoxicação provocados pelo ametryn em plantas de pepino (Cucumis sativus)

\begin{tabular}{|c|l|}
\hline Nota & \multicolumn{1}{|c|}{ Descrição dos sintomas } \\
\hline 0 & Ausência de intoxicação nas plantas \\
\hline 2 & $20 \%$ de intoxicação nas plantas \\
\hline 4 & $40 \%$ de intoxicação nas plantas \\
\hline 6 & $60 \%$ de intoxicação nas plantas \\
\hline 8 & $80 \%$ de intoxicação nas plantas \\
\hline 10 & $100 \%$ todas as plantas mortas \\
\hline
\end{tabular}


na Figura 1, os cromatogramas dos extratos da matriz de solo isenta de herbicida, de uma amostra e do padrão do ametryn em acetonitrila encontram-se na Figura 2.

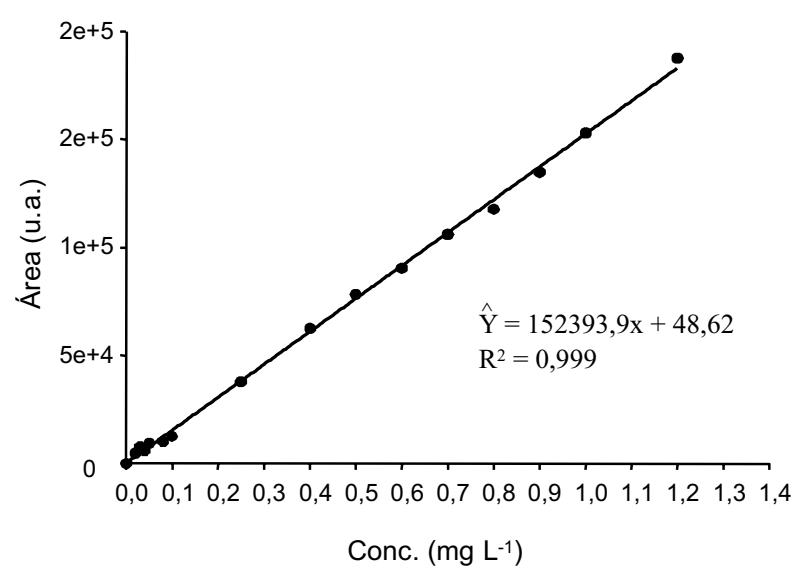

Figura 1 - Curva-padrão do ametryn em acetonitrila determinada por CLAE.
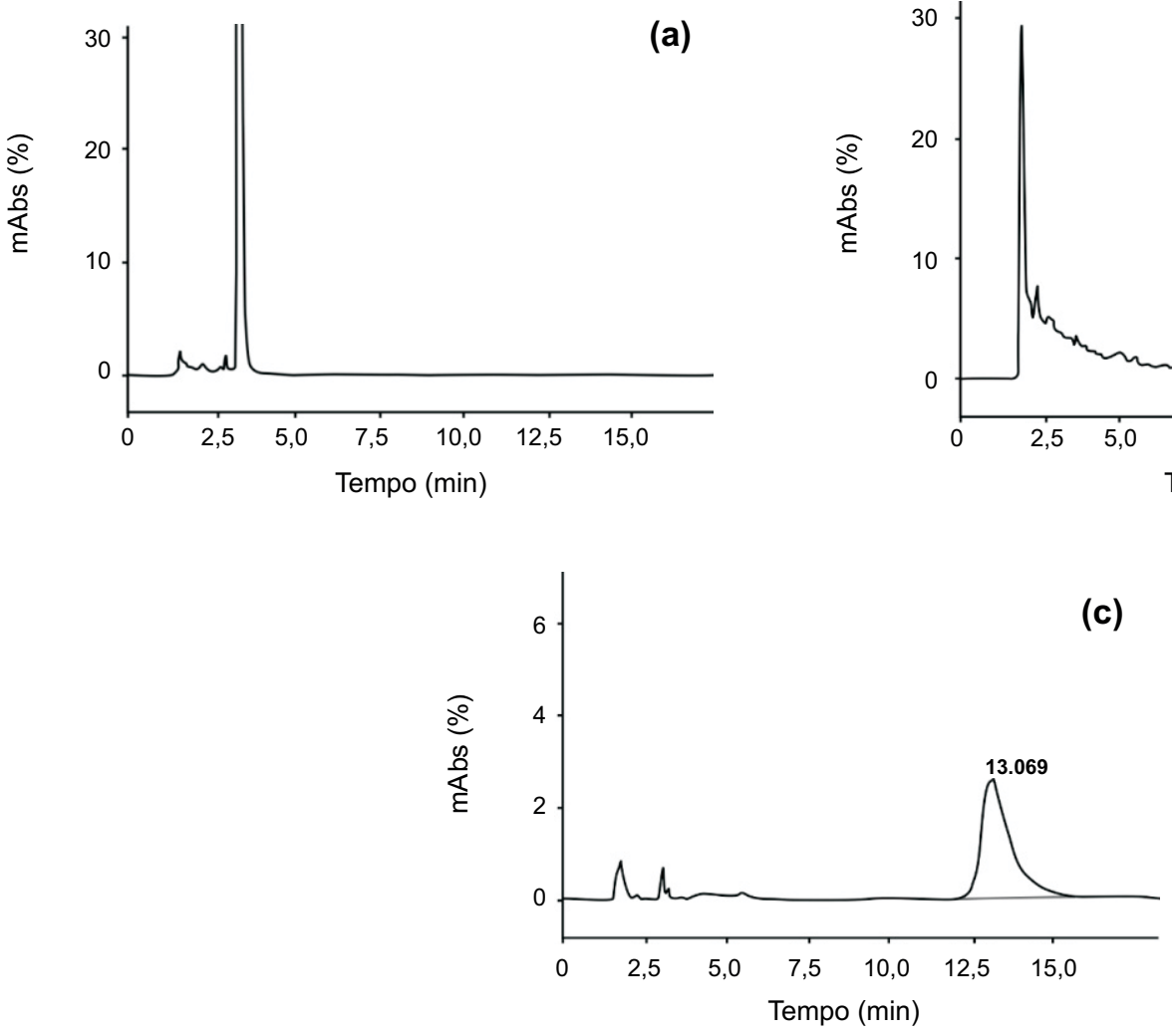

Figura 2 - (a) Cromatograma do extrato de uma matriz de solo isenta do herbicida (branco); (b) cromatograma de uma amostra, após ESL-PBT e recuperação em acetonitrila; (c) cromatograma de um padrão de ametryn em acetonitrila com seu respectivo tempo de retenção, obtidos por CLAE.
Ao analisar os cromatogramas obtidos por CLAE (Figura 4), observa-se que os tempos de retenção do ametryn obtido pela injeção de uma solução-padrão e pela injeção da amostra foram coincidentes. Isso comprova que o pico obtido era realmente do ametryn. Verifica-se ainda, nos espectros obtidos da análise em CG-MS (Figura 3), comprovação com 92\% de certeza de que a molécula presente na amostra era o ametryn. Essa porcentagem de certeza é dada pelo software do equipamento e pode ser observada pela grande semelhança entre os fragmentos do espectro obtido na biblioteca do equipamento e da amostra injetada neste (Figura 4).

A meia-vida $\left(\mathrm{t}^{1} / 2\right)$ do ametryn foi determinada após a quantificação do herbicida a cada intervalo de cinco dias, para o LVA e para o PVA. Foram plotados os gráficos, segundo a equação $\ln \mathrm{C}_{(\mathrm{t})}=-\mathrm{kt}+\ln \mathrm{C}_{(\mathrm{t}=0)}$ (Figura 5$)$, onde se verifica que o $t^{1} / 2$ pode ser calculado por modelo linear, ou seja, o aumento da velocidade

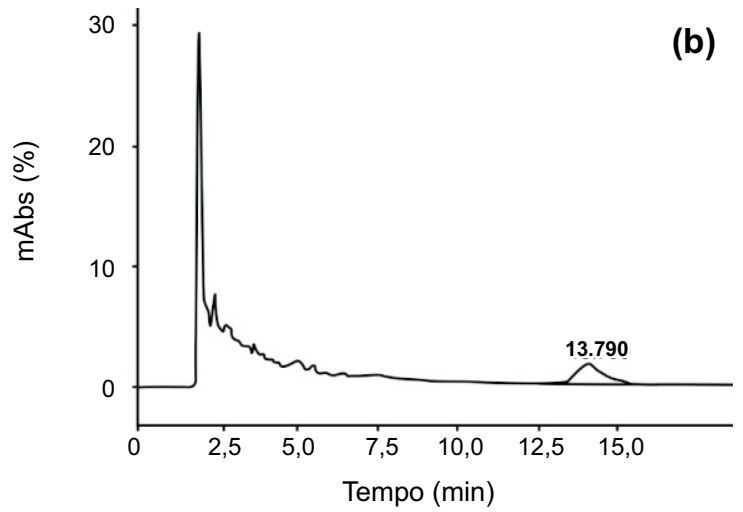

(c) 


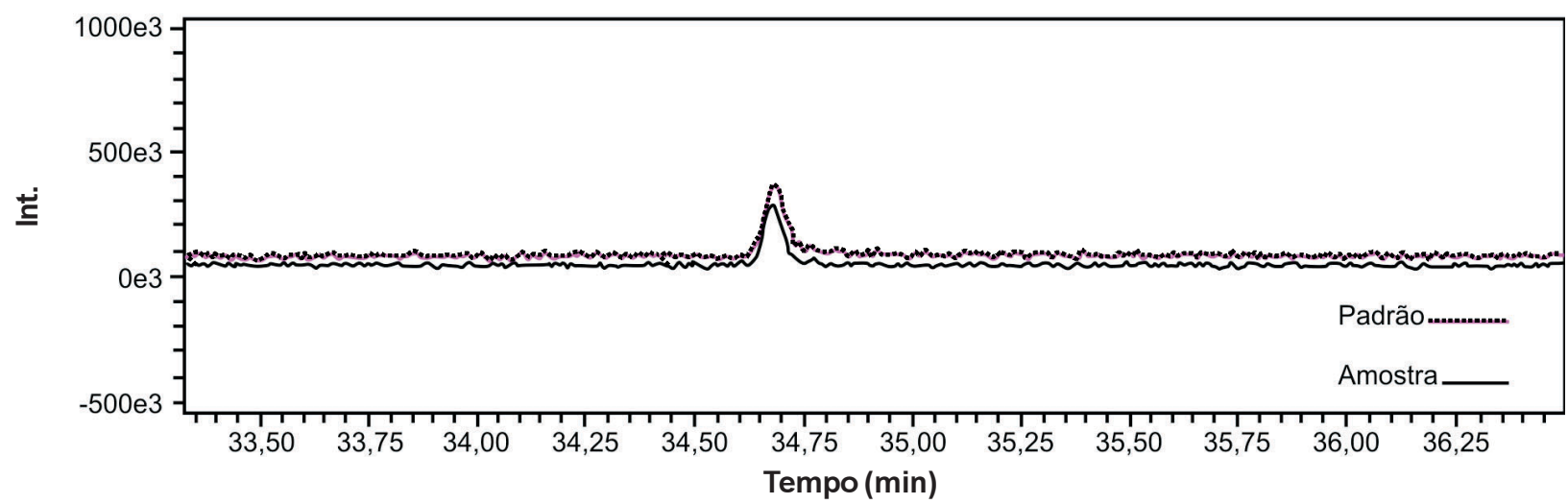

Figura 3 - Cromatogramas obtidos por CG-MS para uma solução-padrão de ametryn $\left(1,0 \mathrm{mg} \mathrm{L}^{-1}\right)$ em acetonitrila e para o extrato de uma matriz de solo (amostra) contendo o herbicida, em acetonitrila.

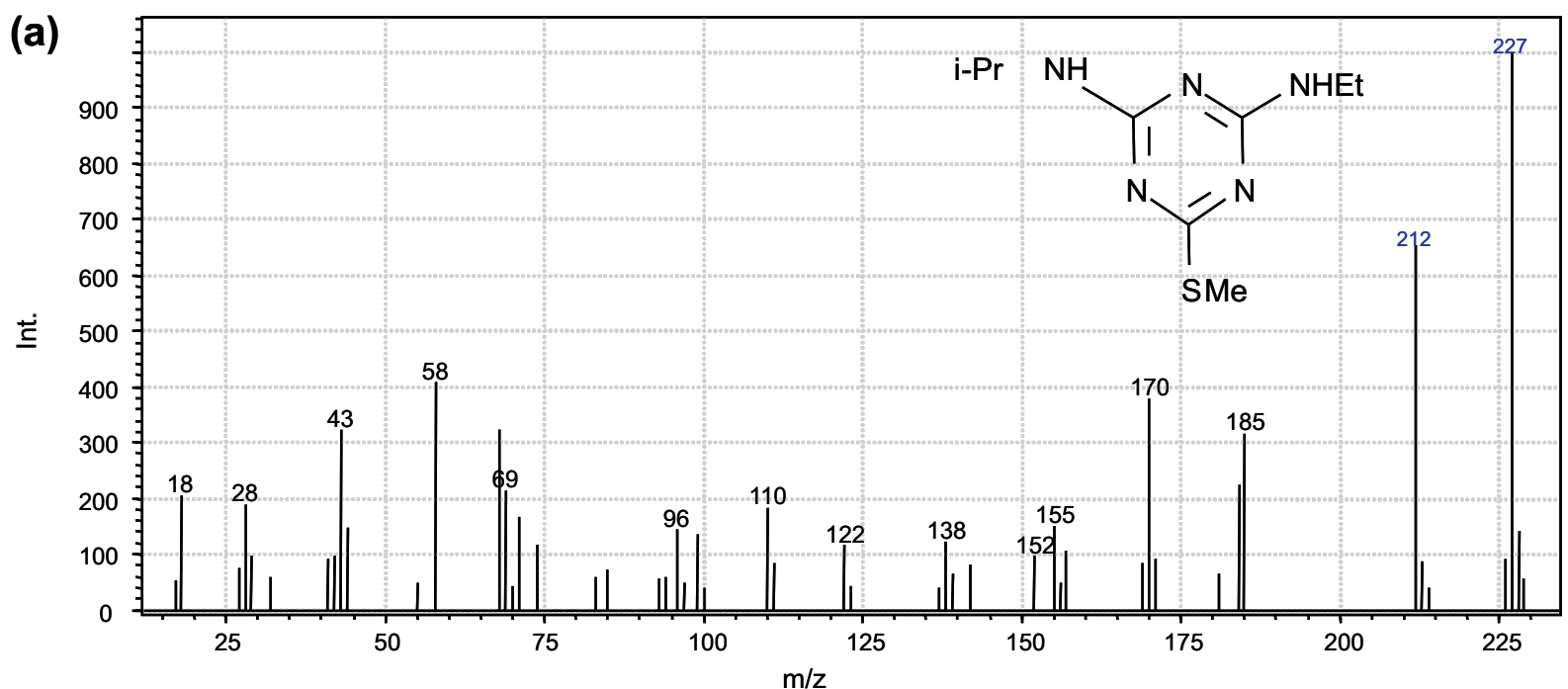

(b)

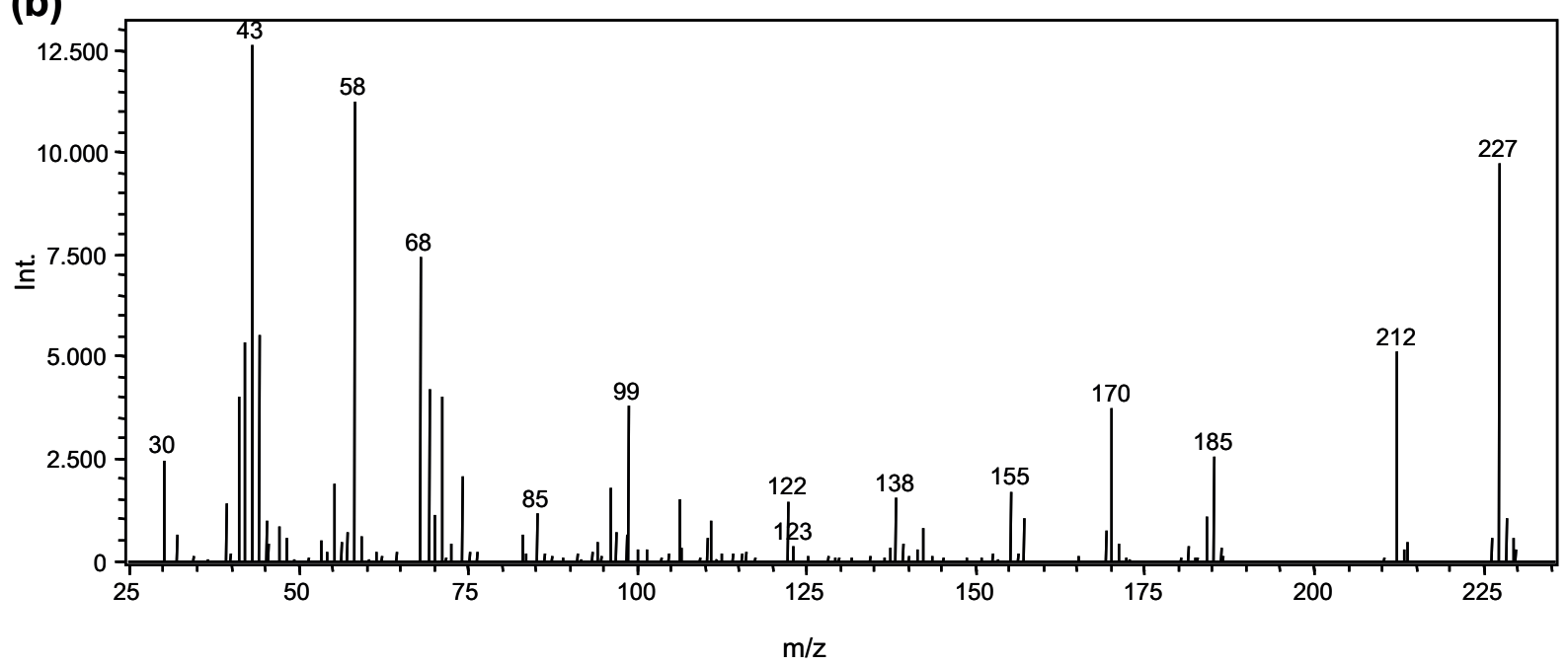

Figura 4 - (a) Espectro de massa da biblioteca do equipamento para o ametryn (1,3,5-triazine-2,4-diamine,N-ethyl-N'-(1-methylethyl)6-(methylthio); (b) espectro de massa da amostra. 
de degradação é diretamente proporcional ao aumento da concentração, e o $\mathrm{t}^{1 / 2}$ não depende da quantidade inicial de herbicida aplicada ao solo (Silva et al., 2007). Observou-se também que o $\mathrm{pH}$ do solo influenciou a degradação do herbicida no solo. No Latossolo VermelhoAmarelo, pH 4,4, a meia-vida do ametryn foi de 26 dias. Observa-se ainda que nesse mesmo Latossolo com o pH corrigido em 4,9 e 5,8, mantidas em condições de clima e umidade semelhantes às do solo de $\mathrm{pH} 4,4$, a meia-vida foi de 19 e 12 dias, respectivamente. Isso pode confirmar o fato de o pH afetar a adsorção do ametryn pelos coloides do solo (Silva et al., 2007), alterando, consequentemente, a sua degradação pela microbiota (Kleinschmitt et al., 2006). Acredita-se que em solos com valores de $\mathrm{pH}$ próximos aos do pka do ametryn,

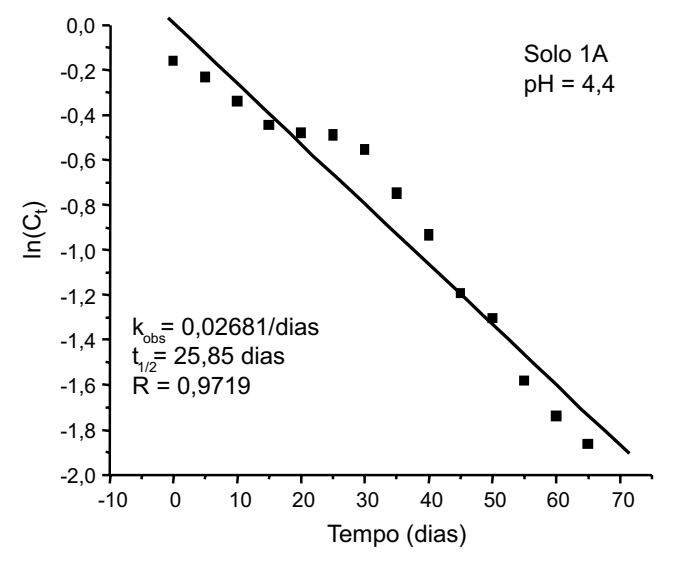

$\mathrm{pH} \mathrm{4,4}$

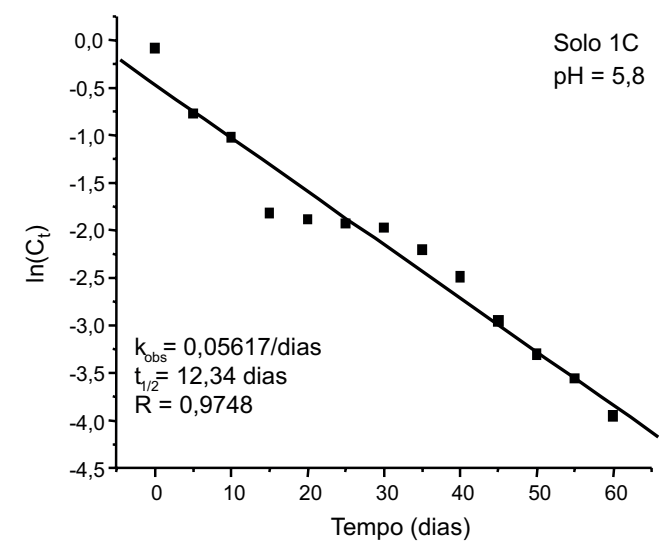

$\mathrm{pH} 5,8$ o herbicida estará mais sorvido pelos coloides do solo, pois parte do produto poderá estar na forma protonada (Silva et al., 2007). Dessa forma, os microrganismos do solo terão maior dificuldade para degradar o herbicida. Kleinschmitt et al. (2006), trabalhando com atrazine, observaram que a variação da taxa de degradação desse herbicida foi inviabilizada pela alta porcentagem de sorção do produto pelos coloides do solo. Esses autores também relataram que a variação do teor de carbono justifica, parcialmente, a variação da taxa de degradação do herbicida.

Foi observado que o ametryn aplicado em um Argissolo Vermelho-Amarelo com pH 5,9 apresentou meia-vida de 11 dias. Esse solo era o que apresentava o maior valor de $\mathrm{pH}$ entre os
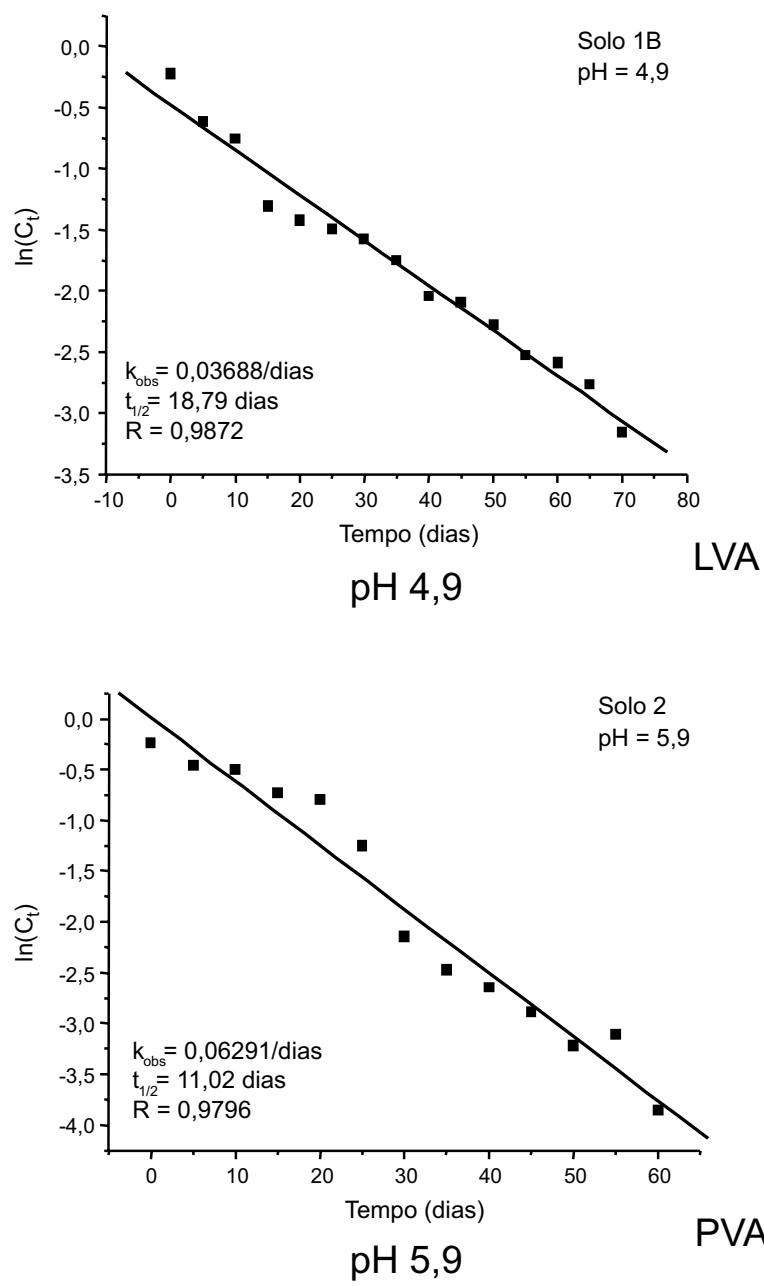

Figura 5 - Estimativas da meia-vida do ametryn em Latossolo Vermelho-Amarelo (LVA) com diferentes valores de pH e em Argissolo Vermelho-Amarelo (PVA). 
estudados, além de conter o maior teor de matéria orgânica (Tabela 1). Esses resultados são corroborados pelos obtidos por Costa et al. (1997), os quais relatam a influência direta da matéria orgânica na degradação do ametryn. Esses autores avaliaram a degradação do ametryn radiomarcado nos carbonos do anel, sob condições de solo esterilizado e não esterilizado, e observaram que a matéria orgânica tem grande influência na degradação do ametryn. Prata (2001) observou que a persistência das moléculas de ametryn foi reduzida com a adição de vinhaça ao solo, pois esta aumentou a atividade e biomassa microbiana, estimulando a mineralização desse herbicida no solo.

Resultados semelhantes também foram observados por Nakagawa \& Andrea (2000) e Kruger et al. (1997), os quais observaram quebra do anel triazínico da atrazine em consequência da ação microbiana. Todavia, em solo Glei Húmico, além da ação dos microrganismos na conversão da atrazine em metabólitos, a degradação química foi responsável por boa parte do processo de degradação desse herbicida no solo (Blumhorst \& Weber, 1994; Andrea et al., 1997; Nakagawa \& Andréa, 2000).

Os resultados obtidos no ensaio biológico (Figura 7) confirmaram os da quantificação dos extratos por cromatografia, indicando maior persistência do ametryn no LVA com valores de $\mathrm{pH}$ menores $(4,4$ e 4,9). Foi observada persistência do ametryn no LVA nas referidas condições até 90 dias após a aplicação do herbicida (DAA), causando intoxicação de 100\% na planta indicadora (Cucumis sativus). Contudo, nas amostras do LVA com $\mathrm{pH}$ 5,8 e no PVA com pH 5,9, não foram observadas intoxicações na planta indicadora aos 90 DAA. Isso comprova a degradação mais rápida do ametryn em solos com $\mathrm{pH}$ mais elevado (Figura 6).

Os sintomas de intoxicação verificados no $t_{0}, t_{15}, t_{30}$ e $t_{45}$ após a aplicação do produto no LVA pH 5,8 são visualizados na Figura 7. Observa-se que o ametryn causou leve intoxicação na planta de pepino (10\%) quando essa espécie foi semeada 15 dias após a aplicação (DAA) e que não causou nenhuma intoxicação na planta indicadora (pepino) a partir dos 30 DAA, confirmando a baixa persistência $(\mathrm{t} 1 / 2=12$ dias) nesse solo (Figura 7 ).

Conclui-se que a degradação do ametryn é maior em solos com maiores valores de $\mathrm{pH}$ e com maior teor de matéria orgânica. $\mathrm{O} \mathrm{t}^{1 / 2} \mathrm{~d}$ do ametryn foi de aproximadamente 26, 19, 12 e 11 dias para o LVA pH 4,4; LVA pH 4,9; LVA

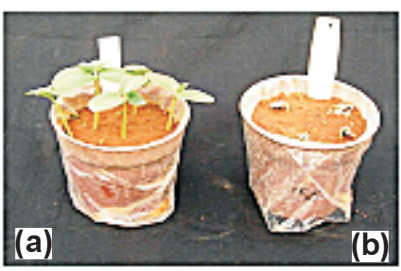

LVA pH 4,4 ( $\mathrm{t}=90)$

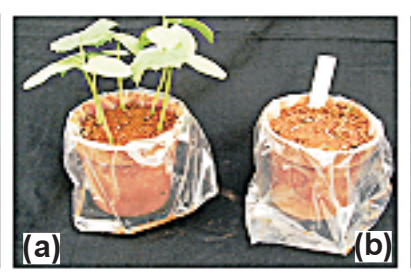

LVA pH 4,9 $(\mathrm{t}=90)$

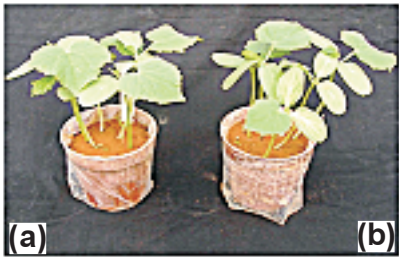

LVA pH 5,8 $(t=90)$

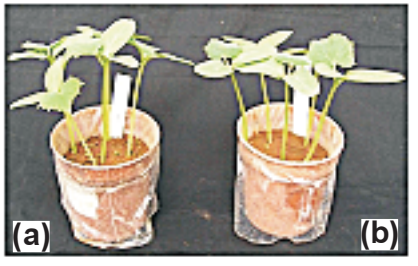

PVA pH 5,9 $(t=90)$

Figura 6 - Intoxicação em plantas de pepino causada pelo ametryn na dose de 2,5 $\mathrm{kg} \mathrm{ha}^{-1}$ aos $90 \mathrm{DAT}\left(\mathrm{t}_{90}\right)$, aplicado no LVA pH 4,4, LVA pH 4,9, LVA pH 5,8 e PVA pH 5,9.

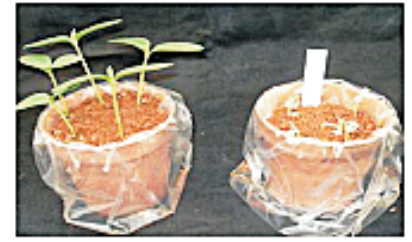

LVA pH 5,8 $(\mathrm{t}=0)$

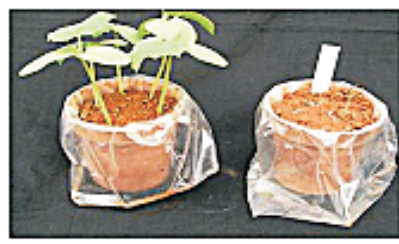

LVA pH 5,8 $(\mathrm{t}=15)$

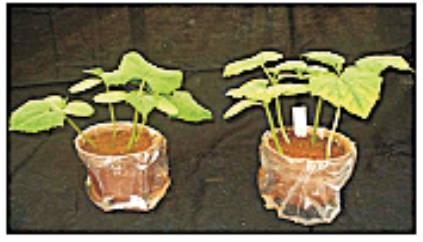

LVA pH 5,8 $(\mathrm{t}=30)$

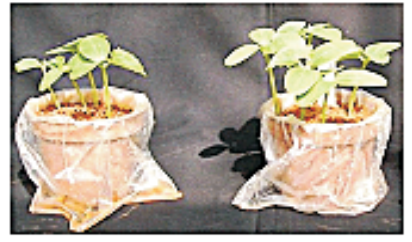

LVA pH 5,8 $(\mathrm{t}=45)$

Figura 7 - Intoxicação em plantas de pepino causada pelo ametryn na dose de 2,5 $\mathrm{kg} \mathrm{ha}^{-1}$, cultivadas em LVA, aos 0, 15, 30 e 45 dias após a aplicação desse herbicida. 
pH 5,8; e PVA 5,9, respectivamente. O teste biológico confirmou os resultados obtidos pela cromatografia líquida quanto à persistência do herbicida no solo.

\section{LITERATURA CITADA}

ANDRÉA, M. M. et al. Effect of temperature on dissipation of [14C] atrazine in a brasilian soil. Pesq. Agropec. Bras., v. 32 , n. 1, p. $95-100,1997$.

BLUMHORST, M. R.; WEBER, J. B. Chemical versus microbial degradation of cynazine and atrazine in soil. Pest. Sci., v. 42, n. 1, p. 79-84, 1994.

BRITO, N. M. et al. Validação de métodos analíticos: estratégia e discussão, pesticidas: Ecotoxicol. Meio Amb., v. 13, n. 1, p. $129-146,2003$

CALDERBANK, A. The occurrence and significance of bound pesticide residues in soil. Rev. Environ. Cont. Toxicol., v. 108, n. 1, p. 71-103, 1989.

COSTA, M. A. et al. Influência da adição de palha de cana-deaçúcar na degradação de ${ }^{14} \mathrm{C}$-ametrina em solo areia quartzosa. Sci. Agric., v. 54, n. 3, p. 117-122, 1997.

DE PAULA, R. T. Mobilidade de atrazine e ametryn em Latossolo Vermelho-Amarelo. 2007. 105 f. Dissertação (Mestrado em Agroquímica) - Universidade Federal de Viçosa, Viçosa, MG, 2007.

EMPRESA BRASILEIRA DE PESQUISA AGROPECUÁRIA - EMBRAPA. Centro Nacional de Pesquisa de Solos. Manual de métodos de análise de solo 2.ed. Rio de Janeiro: 1997. 212 p.

EUROPEAN WEED RESEARCH COUNCIL - EWRC. Report of the $3^{\text {rd }}$ and $4^{\text {th }}$ meetings of EWRC - Comittee of Methods in Weed Research. Weed Res., v. 4, n. 1, p. 88, 1964.

EXTENSION TOXICOLOGY NETWORK - EXTOXNET. Pesticides information profiles. Disponível em: $<$ http:// www.extoxnet.orst.edu/pips/ametryn.htm $>$ Acesso em: Maio de 2007

FILIZOLA, H. F. et al. Monitoramento e avaliação do risco de contaminação por pesticidas em água superficial e subterrânea na região de Guaíra. Pesq. Agropec. Bras., v. 37, n. 5, p. 659-667, 2002.

GEVAO; B. et al. Bound pesticide residues in soils: a review. Environ. Pollut., v. 108, n. 1, p. 3-14, 2000.

GRAHAM-BRYCE, I. G. The behaviour of pesticides in soil. In: GREENLAD, D. J.; HAYES, M. H. B. (Ed.). The chemistry of soil processes. New York: Wiley, 1981. p. $621-670$
GUSTAFSON, D. I. Groundwater ubiquity score: a simple method for assessing pesticide leachibility. Environ. Toxicol. Chem., v 8, n. 4, p. 339-357, 1989

INMETRO - Normalização e qualidade industrial Orientações sobre validação de métodos de ensaios químicos DOQ-CGCRE-008, março, 2003.

KLEINSCHMITT, A. R. B. et al. Dessorção do herbicida atrazina e atividade microbiana em duas classes de solos do Estado do Rio Grande do Sul. Ci. Rural, v. 36, n. 6, p. $1794-1798,2006$

KRUGER, E. L. et al. Organic chemicals in the environment comparative fates of atrazine and deethylatrazine in sterile and non-sterile soils. J. Environ. Quality, v. 26, n. 1, p. 95-101, 1997.

MITCHELL, C. et al. Sedments, nutrients and pesticide residues in event flow conditions in strams of the mackaay whitsunday region, Austrália. Marine Poll. B., v. 51, n. 1, p. $23-36,2005$

MONTEIRO, R. T. R. et al. Projeto Políticas Públicas. In TAUK-TORNISIELO, S. M.; ESQUIERRO, J. C. (Org.). Bacia do Rio Corumbataí: aspectos socioeconômicos e ambientais. Rio Claro: Biblioteca da Unesp - Campus de Rio Claro/SP, 2008. p. 5-178.

NAKAGAWA, L. M.; ANDREA, M.M. Degradação e formação de resíduos não-extraíveis ou ligados do herbicida atrazina em solo. Pesq. Agropec. Bras., v. 35, n. 8, p. $1509-$ 1515,2000

PRATA, F. et al. Degradação e sorção de ametryn em dois solos com aplicação de vinhaça. Pesq. Agropec. Bras., v. 36, n. 7, p. $975-981,2001$.

RIBANI, M. et al. Validação em métodos cromatográficos e eletroforéticos. Química Nova, v. 27, n. 5, p. 771-780, 2004.

SILVA, A. A. et al. Herbicidas: comportamento no solo. In SILVA, A. A.; SILVA, J. F. (Ed.) Tópicos em manejo de plantas daninhas. Viçosa, MG: Universidade Federal de Viçosa, 2007. p. 189-248.

SINGH, N. Organic manure and urea effect on metolachlor transport through packed soil columns. J. Environ. Quality, v. 32, p. 1743-1749, 2003.

VIEIRA, H. P. et al. Otimização e validação da técnica de extração líquido-líquido com partição em baixa temperatura (ELL-PBT) para piretróides em água e análise por CG.

Quimica Nova, v. 30, n. 3, p. 535-540, 2007.

VIVIAN, R. et al. Adsorção e dessorção de trifloxysulfuronsodium e ametryn em solos brasileiros.

Planta Daninha, v. 25, n. 1, p. 97-109, 2007. 